\title{
Un arquitecto integral
}

I.silva@utem.cl

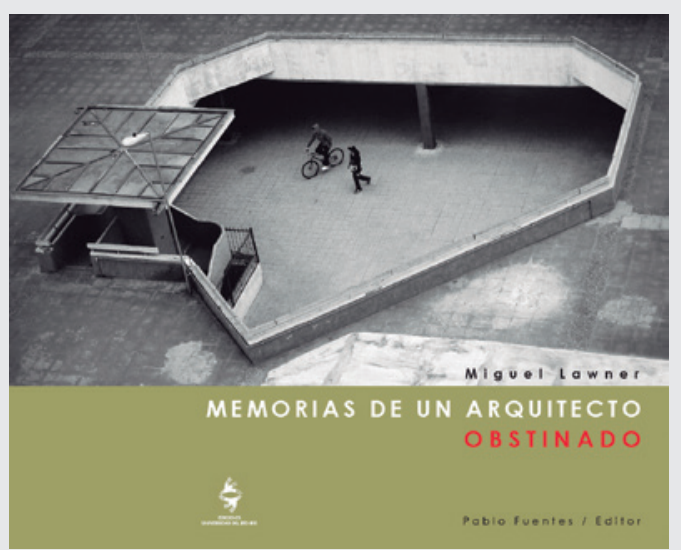

"MIGUEL LAWNER MEMORIAS DE UN ARQUITECTO OBSTINADO"

Miguel Lawner Steiman

ISBN 978-956-9275-00-5

2013

\begin{abstract}
En los últimos años ha aumentado la necesidad de - conocer y apreciar las obras arquitectónicas de nuestro pasado reciente, ya que nos ayuda a develar nuestra imprecisa identidad local que, frecuentemente, es entendida de manera difusa y superficial. En este contexto la publicación de las memorias del arquitecto Miguel Lawner, es un gran aporte al conocimiento y valoración de la Arquitectura Moderna realizada en Chile, ya que en este libro, expone documentos originales y fotografías de su importantísima obra. En este sentido cabe destacar, que esta no es una publicación monográfica, ni un texto analítico que estudia su obra en profundidad, sino que es un conjunto de escritos escogidos, sobre hechos públicos y privados en los cuales él ha desempeñado un rol principal en el transcurso de su vasta y comprometida labor profesional. La reciente distinción a Miguel Lawner como Premio Nacional de Arquitectura hace aún más oportuno recuperar un documento que nos aproxima a su obra, reflexiones y formas de entender la disciplina y su compromiso social.
\end{abstract}

El texto editado por Pablo Fuentes y publicado en conjunto por la Universidad del Bío-Bío, Universidad de Chile y la editorial LOM, se organiza en ocho capítulos correlativos, abarcando desde principios del año 1946 hasta finales del año 2011 . Los primeros tres capítulos son los más extensos del libro y describen sucesivamente su etapa de formación, sus proyectos de arquitectura realizados en Chile y su participación como director de la CORMU en el gobierno de la Unidad Popular. Los otros cinco capítulos son una narración de las vicisitudes de su vida desde cuando fue recluido en Isla Dawson, su exilio durante nueve años en Dinamarca, sus clases en la Escuela de Arquitectura de Copenhague, su retorno a Chile en marzo de 1984 y su trabajo para seguir aportando a la labor profesional durante los gobiernos democráticos.

Lawner comienza sus memorias relatando los acontecimientos que ocurrieron durante su ingreso a la Facultad de Arquitectura de la Universidad de Chile, en marzo de 1946, donde los alumnos mantenían una huelga desde el año anterior, exigiendo la reforma a los planes de estudios para que concordaran con la nueva realidad económica y social que vivía el país en esa época. Para poder superar la huelga, las autoridades de la Universidad se vieron en la obligación de realizar cambios profundos en la enseñanza e instauraron un nuevo sistema pedagógico fundamentado en los lineamientos de la Escuela Activa, el cual se aplicó en cada asignatura según sus características específicas y se manifestó preferentemente en el Taller Central.

Al mismo tiempo, para enfatizar aún más el nuevo perfil de enseñanza, los estudiantes se inspiraron en algunos conceptos de la BAUHAUS dirigida por Hannes Meyer, a través del arquitecto húngaro Tibor Weiner, quien sentó las bases de lo que se denominaría el Arquitecto Integral, que debía entender a la perfección los aspectos filosóficos, plásticos y técnicos, propios de la disciplina y recrear con un lenguaje actualizado los valores permanentes de la arquitectura (p. 29). Así, en el Taller Central, Lawner cursó tercer año con el profesor Mauricio Despuy, cuarto año con Héctor Mardones y quinto año con Simón Perelman, titulándose en 1954, con un proyecto realizado en la "Hacienda del pueblo de Hospital".

Después de finalizados sus años de formación, Lawner relata su etapa de trabajo profesional en la oficina BEL arquitectos, que fundó en 1956, con su esposa Anamaría Barrenechea y Francisco Ehijo, ambos compañeros de generación en la universidad. En este sentido cabe destacar que como bien plantea Osvaldo Cáceres, en esos años la mayor parte de los arquitectos, especialmente los que no disponían de relaciones familiares con apoyo económico, al terminar sus estudios tuvieron en los concursos públicos de arquitectura una posibilidad de acceder a encargos de envergadura, por lo que esta modalidad, significó en la práctica una importante fuente de trabajo para el gremio, además de una excelente alternativa de generar proyectos con una gran calidad arquitectónica. En la importante obra de BEL arquitectos, destaca la obtención del primer lugar en los concursos realizados para la construcción de la población Abate Molina en Talca, los Colegios Regionales Universitarios de Talca y Temuco, el Instituto Nacional de Capacitación (INACAP) en Hualpensillo, el Conjunto de viviendas Inés de Suárez y el Edificio Consistorial de la Municipalidad de Lo Prado, entre muchos otros.

Además de su arduo trabajo disciplinar, entre sus páginas se distingue su comprometida labor gremial, política y docente. Perteneció al colegio de arquitectos en el cual participó activamente para mejorar las condiciones de vida de los trabajadores, en el ámbito político militó en el partido comunista y como profesor dictó clases en le facultad de Arquitectura de la Universidad de Chile, hasta el año 1963, cuando fue exonerado junto a un gran número de profesores que defendían la combinación de la labor académica con el trabajo profesional. Esta experiencia lejos de amilanar el espíritu reformador de estos profesores, sirvió como detonante para la creación de la revista AUCA que se convertiría en un referente en los temas de Arquitectura, Urbanismo, Construcción y Arte, y sintetizó la visión integral que ellos asumieron para el desarrollo de la arquitectura en Chile (p. 160).

Todo su compromiso por construir una sociedad más igualitaria a través de la Arquitectura Moderna se vio reforzada cuando en 1970 fue designado Director Ejecutivo de la Corporación de Mejoramiento Urbano (CORMU), organismo que entre unas de sus prioridades pretendía generar "Viviendas dignas, para hombres dignos", y se incentivaba la construcción en altura en los sectores populares, planteando que esta tipología era sinónimo de privacidad familiar y que a través de ella existía un mejor aprovechamiento del espacio y de los equipamientos. Con este enfoque se desarrollaron conjuntos habitacionales en todo el territorio nacional, destacando en la región metropolitana los conjunto Población Santa Anita, en Quinta Normal; Cuatro Álamos, en Maipú; Remodelación Plaza Chacabuco, en Independencia; Remodelación Tupac Amaru, en Santiago Centro y la Villa Compañero Ministro Carlos Cortés, en la comuna de Las Condes (p. 179)

Al examinar las memorias de este arquitecto obstinado, percibimos que su trabajo involucró a toda una generación de arquitectos comprometidos con el bienestar colectivo que utilizaron la arquitectura como una eficaz herramienta para construir un mundo mejor. Asimismo, nos muestran a un hombre valiente que nunca claudicó en sus principios e hizo suyos los ideales de la nueva arquitectura. También, nos exhibe a un profesional con espíritu crítico que incluso en el epílogo de su libro nos advierte sobre el excesivo formalismo de la arquitectura actual, carente de rigor constructivo y realiza un llamado a las escuelas de arquitectura para aumentar la enseñanza de los cursos técnicos, incluyendo los cálculos de estructuras, que son fundamentales para la edificación en un país sísmico.

Finalmente, no cabe duda que analizar la obra de Miguel Lawner a través de sus memorias es relevante para entender mejor su labor disciplinar, ya que recogen un itinerario profesional e intelectual en sus diferentes facetas de arquitecto, político y escritor, que ha sido recientemente reconocida con el Premio Nacional de Arquitectura 2019, debido a su inmutable trayectoria ética y social, que ha cristalizado una herencia arquitectónica fundamental de nuestro patrimonio. 